Красный: электрические отходы

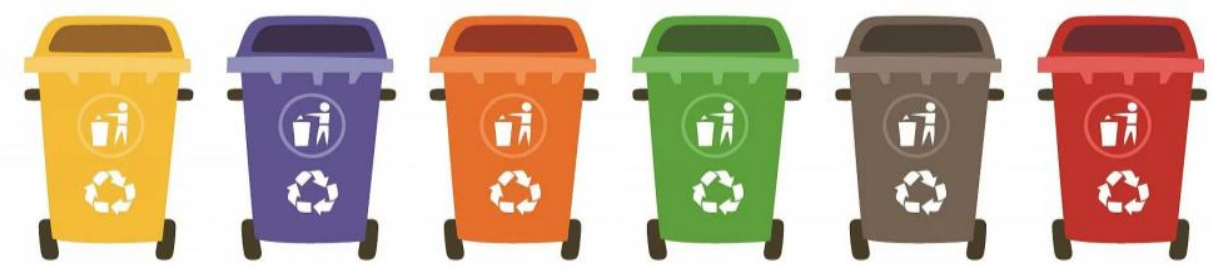

\title{
Предлагаемые отходы:
}

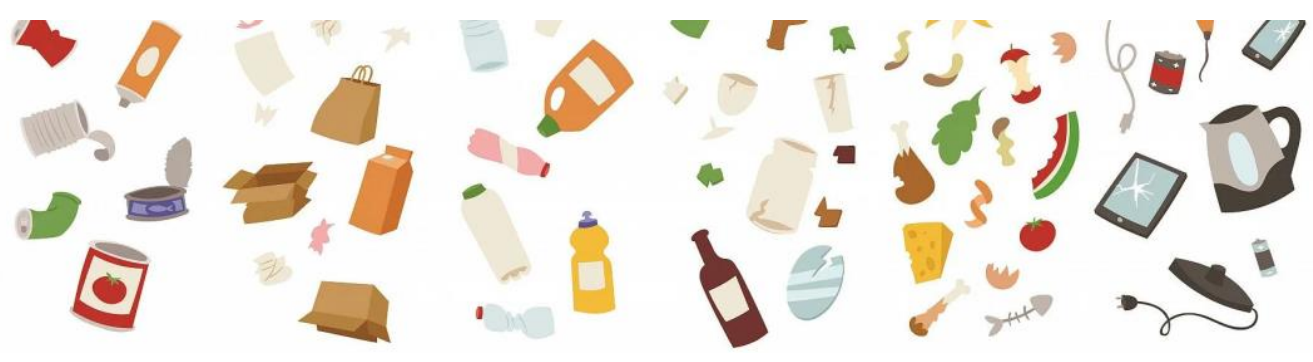

Практическая работа № 3.

Название: Экологичность полиуретана

Цель работы: изучить состав и влияние на природу и организм человека полиуретана.

Оборудование и материалы: средства связи с доступом в интернет.

Ход работы: cheloveka/

1. Перейти по ссылке http://msel.ru/articles/vred-poliuretana-dlya-zdorov-ya-

2. В Вимательно прочитать статью

3. Ответить на вопросы:

a) Для изготовления каких изделий применяется полиуретан?

b) Из каких соединений получают полиуретан?

c) Какие вещества выделяются компонентами, входящими в состав полиуретана?

d) Как влияют на организм человека фенолы и формальдегиды?

е) После прочтения данной статьи, какой вывод можно сделать о вреде полиуретана?

Результаты (требования к оформлению):

Оформить в тетради. Ответы на вопросы должны идти по порядку.

Критерии оценивания:

Правильно даны ответы на вопросы.

Выводы: учащиеся должны сделать вывод о токсичности полиуретана.

Ковалева Е.Ю.

Применение дистанционного обучения и образовательных платформ при изучении иностранных языков в вузе

Финансовый Университет при Правительстве РФ (Россия, Омск)

doi: $10.18411 / l j-02-2021-138$

idsp: ljournal-02-2021-138

\section{Аннотация}

В данной статье рассматривается дистанционная форма обучения студентов вузов и образовательные платформы как один из способов ее осуществления. В 
частности, дается характеристика и описываются возможности платформы Mirapolis, которая использовалась в Финуниверситете во время эпидемии коронавируса. Также в статье говорится об особенностях применения технологий дистанционного обучения с учетом специфики дисциплины «Иностранный язык».

Ключевые слова: дистанционное обучение, образовательная платформа, интерактивное взаимодействие, вебинар, информационные технологии.

\section{Abstract}

This article considers the distance learning of university students and educational platforms as one of the ways to implement it. In particular, the characteristics and capabilities of the Mirapolis platform, which was used at the Financial University during the coronavirus epidemic, are described. The article also discusses the features of the use of distance learning technologies, taking into account the specifics of the discipline "Foreign language".

Key words: distance learning, educational platform, interactive communication, webinar, information technology.

Ситуация, с которой мы столкнулись весной 2020 года, показала, что система традиционного обучения, достаточно эффективная в прошлом, не всегда способна полностью удовлетворять потребности современных реалий. В марте 2020 года все высшие учебные заведения нашей страны были вынуждены организовать обучение в дистанционной форме в связи с эпидемией коронавируса. Дистанционное обучение это форма обучения, которая способна дополнять любую из видов подготовки на расстоянии: очную, заочную или вечернюю. Благодаря этой системе, учащиеся могут осваивать новые материалы, консультироваться с преподавателями, выполнять контрольные и экзаменационные работы с помощью своего домашнего компьютера [3]. Студенты имеют возможность пользоваться разнообразными ресурсами учебного заведения, самостоятельно организовать свою работу при помощи обучающих средств и компьютерных программ, но ведущая роль по-прежнему сохраняется за преподавателем.

Основным принципом дистанционного обучения является непосредственное интерактивное взаимодействие учащегося с преподавателем. Дистанционное обучение ориентировано, прежде всего, на организацию и проведение виртуальных занятий, которые были бы понятны и удобны для обучаемых. Чаще всего они проводятся в форме интернет-видеоконференций, вебинаров. Следует отметить, что современные технологии, позволяющие одновременно передавать видеоизображение, звук, слайдовую и графическую информацию, тон от преподавателя к обучаемому и обратно, помогают создать эффект очного занятия и тем самым достичь необходимого результата. При дистанционном обучении учащийся находится в непрерывном контакте с преподавателем, а иногда и с другими учащимися. Помимо этого, происходит постоянный контроль знаний в форме компьютерного тестирования, опросов.

Сегодня мы можем выделить образовательные платформы как один из способов осуществления дистанционного обучения. Они позволяют людям со всего мира учиться в удобное время в любом месте, повышать свою квалификацию. Их насчитывается не один десяток, но в качестве основных можно назвать следующие образовательные платформы:

- Futurelearn

- EdX

- Coursera

- Skyeng

— Intel Education Galaxy и другие [3]. 
В высших учебных заведениях России широкое распространение получили системы управления обучением Learning Management Systems (LMS). В Финансовом университете при Правительстве РФ с марта текущего года из-за пандемии коронавируса обучение осуществлялось при помощи платформы Mirapolis LMS. Хотелось бы подробнее остановиться на возможностях данной системы и дать ее краткую характеристику. Для организации процесса обучения для нас представляют интерес следующие возможности данной платформы:

- создание неограниченного количества ролей для разграничения прав доступа;

— управление и учет результатов дистанционного, очного, заочного и смешанного обучения;

- создание программ обучения (составных курсов);

— проведение вебинаров, добавление вебинаров в составные курсы;

- проведение тестирования и опросов;

- гибкая настройка рассылок и уведомлений;

— обмен сообщениями между пользователями.

В систему можно загрузить готовые электронные курсы стандартов SCORM 1.2, SCORM 2004, AICC и Tin Can и импортировать QTI-тесты. SCORM - это международный стандарт для создания электронного курса. Если курс опубликован в SCORM, то можно быть уверенным, что его «поймет» практически любая система дистанционного обучения. По сути, SCORM - это свод технических правил. В нем рассказано, как сделать курс, который заработает на любой платформе: подробно описана структура электронного урока, принципы его взаимодействия с системой обучения. Помимо SCORM системы дистанционного обучения используют и другие форматы в зависимости от целей и задач обучения, такие как Tin Can, cmi5, aicc. Форматы курсов в дистанционном обучении определяют порядок взаимодействия платформ дистанционного обучения с учебным контентом, хранящимся на сервере. Электронные учебные материалы создают в форматах SCORM, Tin Can cmi5, aicc, чтобы они могли работать на всех системах дистанционного обучения. Эти форматы - устоявшийся стандарт, как .docx .pdf для текстовых документов.

Кроме того в медиатеку можно добавлять любое количество электронных документов, презентаций и видеороликов. Также в системе можно создать типовое мероприятие для учета результатов очного обучения. В карточке мероприятия множество настроек для описания мероприятия, приема заявок, рассылки уведомлений, учета результатов, выдачи сертификатов и т.д.

Тестовые вопросы можно импортировать из QTI-файлов, а также создавать непосредственно в web-интерфейсе системы [5]. QTI (Question and Test Interoperability) - один из стандартов IMS (и один из немногих, которые используются самостоятельно, а не "спрятавшись" в SCORM или AICC), описывающий модели данных и способы описания вопросов и тестов, а также соответствующих результатов, полученных после того, как пользователь ответил на тест или вопрос.

В Омском филиале Финуниверситета занятия проводились в форме вебинаров. У платформы Mirapolis есть свой сервис для проведения вебинаров, который называется Mirapolis Virtual Room. В нем есть все необходимые для проведения вебинаров функции:

- гибкие настройки интерфейса виртуальной комнаты;

- гибкие настройки регистрации и рассылки различных уведомлений;

- гибкие настройки ролей и прав доступа;

- мобильное приложение для просмотра вебинаров в режиме реального времени;

- демонстрация презентаций и электронных документов; 
- проведение аудио и видеоконференций;

- демонстрация рабочего стола (экрана ведущего);

- доска для рисования в режиме реального времени;

— ч чат и опросы для получения оперативной обратной связи;

- запись вебинаров;

- отчеты о посещаемости и результатах опросов, распечатка переписки в чате.

Теперь хотелось бы подробнее остановиться на применении технологий дистанционного обучения при обучении иностранному языку. В первую очередь, необходимо сказать о специфике предмета «Иностранный язык». Она заключается в том, что ведущим компонентом содержания обучения иностранному языку являются способы деятельности - обучение различным видам речевой деятельности: говорению, аудированию, чтению и письму.

Также предмет «Иностранный язык» характеризуется плотностью общения (объём речевой практики). Рамки уроков ограничивают сферы общения на иностранном языке (количество часов в неделю). Некоторые авторы выделяют объём учебных действий, которые необходимы для успешного общения на иностранном языке, как одну из ключевых особенностей дисциплины [2, С.69]. Они объясняют это тем, что высокая плотность общения на протяжении длительного времени обеспечивает и большой объём общения. Эти особенности взаимосвязаны.

Как уже упоминалось ранее, основными особенностями дистанционного обучения являются сетевое (удалённое) взаимодействие всех участников учебного процесса и сравнительно больший объём самостоятельной работы в режиме «Just in time», интерактивность, отбор и структурирование учебного материала (аутентичные тексты), педагогические технологии. Поэтому можно сказать, что специфика предмета «Иностранный язык» соотносится со спецификой дистанционного обучения.

Ресурсы сети Интернет позволяют расширить содержание учебника и просмотр видеоматериалов аутентичной и актуальной информацией (последние политические, экономические, спортивные, культурные события в мире; тексты носителей языка: речи политических деятелей на конференциях, семинарах, информация ведущих телепередач, фильмы, видеоролики, электронные библиотеки). Конечно, использование актуальной информации на занятиях повышает мотивацию студентов к изучению иностранного языка [2, С.70].

Помимо повышения мотивации Интернет и мультимедийные технологии (блог, форум, чат, скайп и т.д.) дают возможность увеличить объём и плотность речевого общения на иностранном языке в устной и в письменной форме. Например, рассмотрим блоги, которые в настоящее время широко используются в образовании. Блог позволяет публиковать различные материалы и дает возможность их чтения. Его также можно использовать как платформу для дистанционного обучения. Поэтому блог способствует решению таких дидактических задач, как обучение различным видам чтения, письму, устной и письменной речи.

Таким образом, данные технологии могут быть использованы в рамках интеграции очного и дистанционного обучения; для создания единой информационнообразовательной среды общего и дополнительного образования, а также в профильном обучении (элективный курс, сетевая модель дистанционного обучения).

Одним из существенных факторов, способствующих овладению студентами иностранным языком, является общение с носителями изучаемого языка, поскольку языковая практика необходима. Далеко не все студенты могут позволить себе дорогостоящие поездки за рубеж с целью изучения языка и погружения в англоговорящую среду. Существуют множество альтернативных способов, таких как социальные сети и сообщества (например, “Coffeestrap", "Speaky", “The Mixxer” и т.д.); форумы на англоязычных сайтах; мобильные приложения для общения (“Tandem”, 
“HelloTalk", “HiNative”); разговорные клубы (часто при языковых центрах); языковой обмен (платформы "Papora", "Mylanguageexchange"); игры MMORPG (в многопользовательских ролевых онлайн-играх общение, как правило, ведется на английском языке).

В современном мире развития информационных технологий люди все больше общаются при помощи различных цифровых устройств (мобильные телефоны, смартфоны, айфоны, планшетные компьютеры и др.). Мобильное обучение, в основе которого лежит современная концепция BYOD- bring your own device и технология "Just in time", позволяет расширить речевую практику на иностранном языке [2, C.70].

В учебных заведениях считаем целесообразным применение дистанционного обучения в следующих направлениях:

— профильное обучение (элективные курсы);

— интеграция формального и неформального образования;

- повышение квалификации преподавателей.

Говоря о перспективах развития дистанционного обучения иностранным языкам, следует выделить ряд аспектов:

- возможность применения текстов из сети Интернет непосредственно в учебном процессе;

- развитие автоматизированных систем интеллектуального диалога приведет к росту объема учебных действий;

- развитие современных информационных технологий будет способствовать дальнейшему повышению плотности общения и росту речевой практики.

Таким образом, в заключении можно сделать вывод и сказать о том, что организация процесса по изучению иностранных языков в дистанционном формате является мотивирующим фактором и, в конечном итоге, способствует достижению цели обучения иностранным языкам: формированию иноязычной коммуникативной компетенции. Кроме того, дистанционное обучение способствует реализации современных образовательных парадигм таких, как индивидуализация и дифференциация учебной деятельности, самообразование и саморазвитие обучаемых. Внедрение информационно-коммуникационных технологий в обучение иностранным языкам делает этот процесс отвечающим требованиям современного образования, актуальным и привлекательным для студентов, экономичным и эффективным для преподавателей. Данные технологии позволяют модернизировать процесс обучения и продуктивно организовать работу студентов, изучающих иностранные языки. Помимо вышеперечисленных достоинств применения ИКТ необходимо подчеркнуть, что они дают возможность совершенствовать образовательный контент по иностранным языкам, использовать и применять на занятиях обширные информационные ресурсы, снабжать обучающихся актуальными и современными методическими материалами, находящимися в их распоряжении благодаря электронной форме.

$$
* * *
$$

1. Бутова А.В., Дубских А.И., Кисель О.В., Возможности электронной образовательной платформы MOODLE для обучения иностранным языкам [Текст] / А.В. Бутова, А.И. Дубских, О.В. Кисель // Современные наукоемкие технологии. - 2019. - № 12-1. - С. 167-171.

2. Владимирова Л.П. Дистанционное обучение иностранным языкам: специфика и перспективы [Текст] / Л.П. Владимирова // Иностранные языки в высшей школе.- 2014. - №2.- С.68-72.

3. Клейменова Е.А. Дистанционное обучение иностранному языку [Электронный ресурс] / Е.А. Клейменова. - Режим доступа: https://nsportal.ru/shkola/inostrannye-yazyki/library/2020/02/03, свободный

4. Насколько эффективны языковые онлайн-платформы [Электронный ресурс] / Режим доступа: https://accent-center.ru/ru/articles/naskolko-ehffektivny-yazykovye-onlajn-platformy.html, свободный

5. Обзор Mirapolis LMS: возможности и решаемые бизнес-задачи [Электронный ресурс] / Режим доступа: https://lmslist.ru/sdo/obzor-mirapolis/, свободный 